\title{
A study of association of cervical length at 18 weeks and 23 weeks gestation in predicting preterm delivery in twin pregnancies
}

\author{
Shilpa Bajpai, Devendra Arora, Sushil Chawla \\ Corresponding author: Dr. Shilpa Bajpai, Senior Resident, INHS Asvini, Near RC Church, Navy \\ Nagar, Colaba, Mumbai, Maharashtra, India; Email : drshilpa_afmc85@yahoo.co.in
}

Distributed under Attribution-Non Commercial - Share Alike 4.0 International (CC BY-NC-SA 4.0)

\begin{abstract}
Background: Twin pregnancy complicates $1.4 \%$ of all pregnancies but accounts for $15 \%$ of neonatal mortality. The ability to predict preterm delivery could allow targeted intervention such as antenatal steroid induction, cervical encerclage and tocolysis, which might improve neonatal outcome. The length of cervix may be useful in predicting the risk of premature delivery, with a shorter cervix predicting a higher risk. Objectives: The present study was undertaken to evaluate the cervical length during 18th and 23rd week period of gestation in twin pregnancy for predicting preterm delivery and also find the correlation between cervical length and occurrence of preterm birth. Method: In this prospective observational study, a total of 69 antenatal patients underwent cervical length screening at 18 weeks and 23 weeks period of gestation at a tertiary level teaching hospital were recruited. 17 women did not deliver at the study site and were lost to follow up. 3 patients have been excluded from the study as they have been electively terminated because of obstetrical reasons. Results: $22.4 \%$ women at 18 weeks period of gestation and $42.9 \%$ women at 23 weeks period of gestation with cervical length $<25 \mathrm{~mm}$ delivered preterm, making the relationship of short cervix to preterm delivery statistically significant $(\mathrm{P}$ value $<0.001)$. Sensitivity was $18.92 \%$ at 18 weeks and sensitivity was $54.05 \%$ at 23 weeks period of gestation while specificity and positive predictive value (PPV) was $100 \%$ at 18 week and 23 weeks period of gestation. Conclusion: The present study shows that there is fair amount of negative correlation between cervical length and the occurrence of pre-term birth. Which means that as the cervical length increases the chance of preterm birth decreases. Shorter the cervix greater is the likelihood of preterm delivery.
\end{abstract}

Keywords: Twin pregnancy, cervical length, preterm delivery, short cervix, gestation.

Twin pregnancy complicates $1.4 \%$ of all pregnancies but accounts for $15 \%$ of neonatal mortality and prematurity is the major cause of neonatal morbidity and mortality. ${ }^{1}$ Spontaneous preterm delivery occurs approximately 7-10 times more commonly in twin than singleton pregnancies and tends to occur at an earlier gestation. ${ }^{2}$ However, delivery before 37 weeks occurs in less than $10 \%$ of pregnancies but accounts for more than $75 \%$ of all neonatal deaths. ${ }^{3}$ Survival of preterm infants is mainly dependent on gestational age at delivery and survival increases from less than $5 \%$ for those born at 23 weeks to more than $95 \%$ by 32 weeks. ${ }^{4,5}$ The risk of severe handicap in survivors decreases from more than
$60 \%$ for those born at 23 weeks to less than $5 \%$ by 32 weeks. ${ }^{4-6}$

The length of cervix may be useful in predicting the risk of premature delivery, with a shorter cervix predicting a higher risk. Transvaginal sonographic (TVS) cervical length at 20 to 24 weeks gestation is supposed to be a predictor of spontaneous preterm birth in asymptomatic women with twin pregnancies. $^{7}$ In one study, 89 women at high risk for premature delivery had TVS measurements of the cervical length taken at least twice between the $15^{\text {th }}$ and $24^{\text {th }}$ weeks of gestation. The authors found that the incompetent cervix can begin to shorten at as early as 15 weeks' gestation and that

Received: $20^{\text {th }}$ April 2020. Peer review completed: $21^{\text {st }}$ July 2020, Accepted: $25^{\text {th }}$ July 2020.

Bajpai S, Arora D, Chawla S. A study of association of cervical length at 18 weeks and 23 weeks gestation in predicting preterm delivery in twin pregnancies. The New Indian Journal of OBGYN. 2021; 7(2): 228-32. 
the rates of cervical shortening were greater in the group with an incompetent cervix than in that with a normal cervix $^{8}$

Furthermore, several studies have shown that ultrasonographic cervical assessment is more accurate than digital examination for identifying cervical changes. But transvaginal cervical length measurement has several technical advantages as it allows better quality and more accurate visualization of the uterine cervix and has fewer limitations than does the trans-abdominal approach. ${ }^{9}$ Hence, in present study cervical lengths was measured by transvaginal sonography during 18th and 23rd week period of gestation and find the association between cervical length and preterm delivery.

\section{Materials and methods}

This prospective observational study was conducted in the Department of Obstetrics and Gynaecology in a tertiary care centre from $1^{\text {st }}$ December 2016 to $1^{\text {st }}$ June 2018. The study was approved by Institutional Ethical Committee. Inclusion criteria were patients with twin pregnancy attending antenatal OPD and who have higher order multiple gestation reduced to twin pregnancy. All cases of previous history of preterm delivery, cervical incompetence, triplet/quadruplet pregnancy and history of uterine malformations were excluded from the study. A total of 69 antenatal patients were recruited after having met the inclusion/exclusion criteria and underwent cervical length screening at 18 weeks and 23 weeks period of gestation. 17 women did not deliver at the study site and were lost to follow up. Three patients have been excluded from the study as they have been electively terminated because of obstetrical reasons as: hypertensive disorders - 1 , inevitable abortion -1 , missed abortion -1 .

All patients had their cervical length measured by transvaginal sonography (TVS) using the $8 \mathrm{MHz}$ transducer at 18 weeks and 23 period weeks of gestation. The women were asked to empty their bladder and examination was carried out in dorsal lithotomy position. The transvaginal ultrasound probe covered with sterile condom was inserted in the anterior fornix of the vagina until an adequate sagittal image of the cervix is visualised. The external os is identified by its triangular echo density and internal os by its ' $\mathrm{V}$ ' shaped appearance. The distance between the two was taken as cervical length. An adequate image for the measurement of cervical length was defined as the visualisation of the internal os, external os and endocervical canal with at least
$75 \%$ of the image occupying the screen. The cervical length was measured in millimetres ( $\mathrm{mm})$ and the measurements were taken twice. The mean of two measurements was taken as the cervical length for that patient.

The primary outcomes of the study were to determine period of gestation at delivery and correlated with cervical length at 18 weeks and 23 weeks gestation. The variables which we considered as: 1) short cervix - cervix $<25 \mathrm{~mm}$, funnelling of the internal os $>1 \mathrm{~cm}$, on speculum examination - detection of the dilatation of internal os with herniation of the membranes. 2) Early preterm delivery delivery between 28 weeks and 33 weeks $\& 6$ days period of gestation. 3) Late preterm delivery - delivery after 34 weeks but before 37 weeks and 6 days period of gestation.

Statistical analyses were performed using SPSS software, version 12.0. The association between cervical length and preterm delivery was assessed by fisher's exact test. A p value of 0.05 was taken as level of significance and $\mathrm{p}<$ 0.001 was taken as statistically highly significant.

\section{Results}

Out of 49 women analyzed in the study, 37 had preterm delivery $(75.5 \%)$, in which $11(22.44 \%)$ patients delivered at 18 weeks and $26(53.06 \%)$ at 23 weeks. There were 11 patients had cervical length $<2.5 \mathrm{cms}$ at 18 weeks period of gestation, for whom the calculated mean gestational age was 33.01weeks. The cervical length further decreased in 10 more patients when they reached the 23 weeks period of gestation, making the mean gestational age as 33.21 weeks as shown in table 1 .

There was significant correlation between preterm delivery and short cervix at 18 weeks and 23 weeks period of

\begin{tabular}{llll}
\hline $\begin{array}{l}\text { Table 1: Association of gestational age at delivery with cervical length at } \mathbf{1 8} \\
\text { weeks and } \mathbf{2 3} \text { weeks period of gestation }\end{array}$ \\
\hline $\begin{array}{l}\text { Cervical length at } \\
\mathbf{1 8} \text { weeks in cm }\end{array}$ & $\begin{array}{l}\text { Number of } \\
\text { patients }\end{array}$ & $\begin{array}{l}\text { Gestational } \\
\text { age (weeks) }\end{array}$ & p-value \\
\hline$\leq 2.5$ & 11 & $33.01 \pm 2.82$ & \\
$2.51-3.00$ & 14 & $34.36 \pm 2.73$ & \\
$3.01-3.50$ & 10 & $36.19 \pm 1.13$ & $<0.001$ \\
$3.51-4.00$ & 12 & $36.77 \pm 1.34$ & \\
$>4.00$ & 2 & $37.57 \pm 0.00$ & \\
\hline Cervical length at & Number of & Gestational & \multirow{2}{*}{ p-value } \\
$\mathbf{2 3}$ weeks & patients & $33.21 \pm 2.68$ & \\
$\leq 2.5$ & 21 & $36.27 \pm 0.80$ & \\
$2.51-3.00$ & 9 & $36.64 \pm 1.42$ & $<0.001$ \\
$3.01-3.50$ & 14 & $37.18 \pm 1.29$ & \\
$3.51-4.00$ & 4 & $36.86 \pm 0.00$ & \\
$>4.00$ & 1 & & \\
\hline
\end{tabular}


The New Indian Journal of OBGYN. 2021 (January-June);7(2)

\begin{tabular}{|c|c|c|c|c|c|}
\hline $\begin{array}{l}\text { Mode of } \\
\text { delivery }\end{array}$ & $\begin{array}{l}\text { CL } 18 \text { weeks } \\
\text { in } \mathrm{cm}\end{array}$ & $\begin{array}{l}\text { Pre term } \\
\text { Yes }\end{array}$ & No & Total & p-value \\
\hline LSCS & $\begin{array}{l}\geq 2.5 \\
<2.5 \\
\text { Total } \\
\end{array}$ & $\begin{array}{l}22 \\
04 \\
26 \\
\end{array}$ & $\begin{array}{l}04 \\
00 \\
04 \\
\end{array}$ & $\begin{array}{l}26 \\
04 \\
30 \\
\end{array}$ & 0.621 \\
\hline Vaginal & $\begin{array}{l}\geq 2.5 \\
<2.5 \\
\text { Total }\end{array}$ & $\begin{array}{l}08 \\
03 \\
11\end{array}$ & $\begin{array}{l}08 \\
00 \\
08\end{array}$ & $\begin{array}{l}16 \\
03 \\
19\end{array}$ & 0.228 \\
\hline $\begin{array}{l}\text { Mode of } \\
\text { delivery }\end{array}$ & $\begin{array}{l}\text { CL } 23 \text { weeks } \\
\text { in } \mathrm{cm}\end{array}$ & $\begin{array}{l}\text { Pre term } \\
\text { Yes }\end{array}$ & No & Total & p-value \\
\hline LSCS & $\begin{array}{l}\geq 2.5 \\
<2.5 \\
\text { Total }\end{array}$ & $\begin{array}{l}15 \\
11 \\
26 \\
\end{array}$ & $\begin{array}{l}4 \\
0 \\
4 \\
\end{array}$ & $\begin{array}{l}19 \\
11 \\
30 \\
\end{array}$ & 0.268 \\
\hline Vaginal & $\begin{array}{l}\geq 2.5 \\
<2.5 \\
\text { Total }\end{array}$ & $\begin{array}{l}2 \\
9 \\
11\end{array}$ & $\begin{array}{l}8 \\
0 \\
8\end{array}$ & $\begin{array}{l}10 \\
9 \\
19\end{array}$ & 0.001 \\
\hline
\end{tabular}

early-rapid shortening, late-shortening, and early shortening with a plateau and each pattern had different risk of $\mathrm{PB}$ while highest risk was in early-rapid shortening group. ${ }^{12}$ However, cervical length assessed in midtrimester asymptomatic twin pregnancies was a poor predictor of $\mathrm{PB}<32$ weeks' gestation. ${ }^{13}$ Within 3 weeks period, a shortening in cervical length $>10 \%$ was found associated with increased risk of PB. ${ }^{14}$ It was reported that risk for $\mathrm{PB}$ was higher in women with cervical dilatation, while short cervical length was independently associated with preterm birth. ${ }^{15}$ A cervical length $\leq 15 \mathrm{~mm}$ was reported as the most optimal cut-off with $81 \%$ specificity and $83 \%$ gestation as shown in table 2

Sensitivity was $18.92 \%$ at 18 weeks and sensitivity was $54.05 \%$ at 23 weeks period of gestation while specificity and positive predictive value (PPV) was $100 \%$ at 18 week and 23 positive predictive value for predicting the true preterm labor. ${ }^{16}$ Likewise, optimal cut off values of CL for preterm labour have varied in various studies ranging from 18 to Table 3: Association of cervical length at 18 weeks and 23 weeks period of gestation and preterm delivery in study group

\begin{tabular}{llll}
\hline \multirow{2}{*}{ CL 18 weeks in cm } & \multicolumn{2}{c}{ Pre term } & Total \\
\cline { 2 - 4 } & Yes & No & 7 \\
\hline$<2.5$ & 7 & 0 & 42 \\
$\geq 2.5$ & 30 & 12 & 49 \\
Total & 37 & 12 & NPV (\%) \\
Sensitivity (\%) & Specificity (\%) & PPV (\%) & 28.57 \\
18.92 & 100.00 & 100.00 & Total \\
\hline \multirow{2}{*}{ CL 23 weeks in cm } & Yes & No & 20 \\
\cline { 2 - 4 } & 20 & 0 & 42 \\
$\geq 2.5$ & 17 & 12 & 49 \\
Total & 37 & 12 & NPV (\%) \\
Sensitivity (\%) & Specificity (\%) & PPV (\%) \\
54.05 & 100.00 & 100.00 & 41.38 \\
\hline
\end{tabular}

$30 \mathrm{~mm}$, however we took $25 \mathrm{~mm}$ as the cut off for $\mathrm{CL}$ which was measured twice at 18 weeks and 23 weeks period of gestation.

There were 11 patients, who had cervical length $<2.5 \mathrm{cms}$ at 18 weeks period of gestation, for whom the calculated mean gestational age was 33.01 weeks. The cervical length further decreased in 10 more patients when they reached the 23 weeks period of gestation, making the mean gestational age as 33.21 weeks. This can be explained by the fact that as pregnancy progresses further, the

weeks period of gestation. Negative predictive value (NPV) was $28.57 \%$ at 18 weeks and NPV was $41.38 \%$ at 23 weeks period of gestation (Table 3 ).

\section{Discussion}

Women with a multiple pregnancy face greater risks for themselves and their infants than women pregnant with one child. Preterm birth accounts for $43.6 \%$ of all twin births, compared with $5.6 \%$ in singleton pregnancies. ${ }^{10}$ Preterm birth $(\mathrm{PB})$ is common in twin pregnancies. Twin pregnancies nonetheless are associated with increased morbidity and mortality, almost always related to the effects of prematurity. ${ }^{11}$

The screening of cervical length by transvaginal ultrasound is a good predictor of PB risk. Women with twin gestation were screened for serial cervical length measurements between 14-18 weeks and 28-32 weeks; it was reported that cervical length had four pattern sas stable, number of women with short cervix increases because the shortening of cervix is a continuous process with the pregnancy advancement. The current study found significant correlation between preterm delivery and short cervix at 18 weeks and 23 weeks period of gestation. Souka et $\mathrm{al}^{17}$ studied cervical length in 215 twin pregnancies at 23 weeks period of gestation and found that cervical length distribution was skewed towards shorter length and the median value was $38 \mathrm{~mm}$. They found that in $11.2 \%$ and $4.2 \%$ of cases, length was up to $25 \mathrm{~mm}$ and up to $15 \mathrm{~mm}$, respectively. Skentou et $\mathrm{al}^{18}$ studied 464 twin pregnancies and found that the cervical length distribution was skewed to the left and the median value was $36 \mathrm{~mm}$. The rate of spontaneous delivery before 33 weeks was inversely related to cervical length at 23 weeks which is similar to present study. 
The New Indian Journal of OBGYN. 2021 (January-June);7(2)

Gibson et al ${ }^{19}$ did transvaginal ultrasound assessments of cervical length serially at 18, 24, 28 and 32 weeks' gestation for 248 twin pregnancies, in which he found that the cervical length $\leq 25 \mathrm{~mm}$ at 18 weeks (LR+ 9.7, sensitivity $14.3 \%$ ) and $\leq 22 \mathrm{~mm}$ at 24 weeks ( $\mathrm{LR}+9.6$, sensitivity $28.6 \%$ ) were the best predictors of preterm delivery. They also concluded that the poor sensitivity of this test makes it unsuitable as a single predictor of preterm delivery, which is similar to present results in which sensitivity was $18.92 \%$ at 18 weeks and sensitivity was $54.05 \%$ at 23 weeks period of gestation. Yang et al ${ }^{20}$ analysed 65 twin pregnancies and measured the cervical length at 22 weeks period of gestation and 24 weeks period of gestation and found out that both cervical length $<30 \mathrm{~mm}$ and cervical funnelling in twin pregnancies under 26 weeks period of gestation are independently and strongly associated with high risk for preterm birth. A long cervix of length $>35 \mathrm{~mm}$, is associated with very low risk $(4 \%)$ of preterm birth. Berghella et al ${ }^{21}$ concluded from their study that transvaginal ultrasound cervical length is clearly superior to the clinically used manual dilatation in predicting preterm labour.

Cervical length is the most reproducible and valid variable for transvaginal ultrasound cervical assessment in prediction of preterm birth. ${ }^{22}$ The addition of funnelling does not improve the prediction based on cervical length alone. In the study by Vendittelli ${ }^{23}$, it was seen that funnelling $(>5 \mathrm{~mm}$ ) was not found to be predictive of preterm labour but cervical length was significantly predictive.

\section{Conclusion}

The present study shows that there is fair amount of negative correlation between cervical length and occurrence of preterm birth, which means that as cervical length increases chance of preterm birth decreases. Also the short cervix is a good predictor of preterm birth in twin pregnancy and can be used as screening method for prediction of preterm labour.

\section{Conflict of interest: None. Disclaimer: Nil.}

\section{References}

1. Chauhan SP, Scardo JA, Hayes E, Abuhamad AZ, Berghella V. Twins: prevalence, problems, and preterm births. Am J Obstet Gynecol 2010; 203 (2010): 305-15.

2. Tanaka K, Yamada K, Matsushima M, Izawa I, Furukawa S, Kobayashi Y, et al. Prediction of spontaneous preterm delivery in asymptomatic twin pregnancies using cervical length and granulocyte elastase. Taiwanese Journal of Obstetrics \& Gynecology 2017; 56(2):188-91.

3. Meis PJ, Goldenberg RL, Mercer BM, Iams JD, Moawad AH, Miodovnik M, et al. The preterm prediction study: risk factors for indicated preterm births. American Journal of Obstetrics and Gynecology. 1998;178(3):562-7.

4. Goldenberg RL, Culhane JF, Iams JD, Romero R. Epidemiology and causes of preterm birth. The Lancet. 2008; 371(9606):75-84.

5. Celik E, To M, Gajewska K, Smith GCS, Nicolaides KH. Cervical length and obstetric history predict spontaneous preterm birth: development and validation of a model to provide individualized risk assessment. Ultrasound in Obstetrics and Gynecology. 2008; 31(5):549-54.

6. Martin JA, Hamilton BE, Sutton PD. Births: final data for 2007, National Vital Statistics Reports 2010; 58:1-85.

7. Agustin Conde-Agudelo A, Romero R, Hassan SS, Yeo L. Transvaginal sonographic cervical length for the prediction of spontaneous preterm birth in twin pregnancies: a systematic review and metanalysis. Am J Obstet Gynecol. 2010; 203(2):128.

8. Guzman ER, Mellon C, Vintzileos AM, Ananth CV, Walters C, Gipson K. Longitudinal assessment of endocervical canal length between 15 and 24 weeks' gestation in women at risk for pregnancy loss or preterm birth. Obstet Gynecol. 1998; 92:31-7.

9. Saini R, Yadav R, Pathak B. Use of cervical length, measured by transvaginal sonography at 22 to 26 weeks, as a predictor of preterm labour in twin pregnancy. Int $\mathrm{J}$ Reprod Contracept Obstet Gynecol. 2018; 7: 3590-5.

10. Patel N, Barrie W, Campbell D. Scottish twin study 1983 - preliminary report. Glasgow: University of Glasgow, Departments of Child Health and Obstetrics, Social Paediatric and Obstetric Research Unit; 1983.

11. Corsello G, Piro E. The world of twins: an update. J Maternal Fetal Neonatal Med. 2010; 23 (Suppl 3): 59-62.

12. Melamed N, Pittini A, Hiersch L, Korzeniewski SS, Romero R, Barrett J. Serial cervical length determination in twin pregnancies reveals 4 distinct patterns with prognostic significance for preterm birth. American Journal of Obstetrics \& Gynecology. 2016; 215(4): 476-476.e11. 
The New Indian Journal of OBGYN. 2021 (January-June);7(2)

13. Pagani G, Stagnati V, Fichera A, Prefumo F. Cervical length at mid-gestation in screening for preterm birth in twin pregnancy. Ultrasound in Obstetrics \& Gynecology. 2016; 48(1): 56-60.

14. Blanc J, Bretelle F. Outilspr'edictifs de l'accouchementpr'ematur'edansune population asymptomatique 'a haut risqué. Journal de Gyn'ecologieObst'etrique et Biologie de la Reproduction. 2016; 45 (10):1261-79.

15. Hiersch L, Melamed N, Aviram A, Bardin R, Yogev Y, Ashwal E. Role of cervical length measurement for preterm delivery prediction in women with threatened preterm labor and cervical dilatation. Journal of Ultrasound in Medicine. 2016; 35(12): 2631- 40.

16. Kunzier NB, Kinzler WL, Chavez MR, Adams TM, Brand DA, Vintzileos AM. The use of cervical sonography to differentiate true from false labor in term patients presenting for labor check. American Journal of Obstetrics \& Gynecology. 2016; 215(3): 372-372.e5.

17. Souka AP, Heath V, Flint S, Sevastopoulou I, Nicolaides KH. Cervical length at 23 weeks in twins in predicting spontaneous preterm delivery. Obstet Gynecol. 1999; 94: 450 - 4.

18. Skentou C, Souka AP, To MS, Liao AW, Nicolaides KH. Prediction of preterm delivery in twins by cervical assessment at 23 weeks. Ultrasound Obstet Gynecol. 2001; 17: 7-10.
19. Gibson JL, Macara LM, Owen P, Young D, Macauley J, Mackenzie F. Prediction of preterm delivery in twin pregnancy: a prospective, observational study of cervical length and fetal fibronectin testing. Ultrasound in Obstetrics and Gynecology. 2004; 23(6): 561-6.

20. Yang JH, Kuhlman K, Daly S, Berghella V. Prediction of preterm birth by second trimester cervical sonography in twin pregnancies. Ultrasound in Obstetrics and Gynecology. 2000 Apr 1; 15(4): 288-91.

21. Berghella V, Tolosa JE, Kuhlman K, Weiner S, Bolognese RJ, Wapner RJ. Cervical ultrasonography compared with manual examination as a predictor of preterm delivery. Am J Obstet Gynaecol. 1997; 177(4): 723-30.

22. Berghella V, Bega G, Tolosa JE, Berghella M. Ultrasound assessment of the cervix. Clin Obstet Gynecol. 2003; 46: 947-62.

23. Vendittelli F, Mamelle N, Munoz F, Janky E. Transvaginal ultrasonography of the uterine cervix in hospitalized women with preterm labor. Int J Obstet Gynecol. 2001; 72: 117-25.

\footnotetext{
Shilpa Bajpai ${ }^{1}$, Devendra Arora ${ }^{2}$, Sushil Chawla ${ }^{3}$

${ }^{1}$ Senior Resident, INHS Asvini, Near RC Church, Navy

Nagar, Colaba, Mumbai, Maharashtra, India;

${ }^{2}$ Professor and HOD Base Hospital, Delhi Delhi Cantt, India; ${ }^{3}$ Professor, Armed Forces Medical College, Pune, Maharashtra, India.
} 